\title{
Resection of anterior mediastinal ectopic pancreas by right thoracoscopy: A case report
}

\author{
HONGLIN ZHAO*, ZIHE ZHANG ${ }^{*}$, XIN LI, JINGHAO LIU, HONGBING ZHANG, GANG CHEN and JUN CHEN \\ Department of Lung Cancer Surgery, Tianjin Key Laboratory of Lung Cancer Metastasis and Tumor Microenvironment, \\ Tianjin Lung Cancer Institute, Tianjin Medical University General Hospital, Heping, Tianjin 300052, P.R. China
}

Received October 8, 2018; Accepted June 10, 2019

DOI: $10.3892 / \mathrm{mco} .2019 .1878$

\begin{abstract}
Ectopic pancreas is uncommon in the anterior mediastinum. Herein, a 32-year-old woman presented to our institution for investigation of an abnormal mediastinal shadow on chest computed tomography. The patient underwent complete surgical resection of the anterior mediastinal mass by right thoracoscopy, and the postoperative pathology examination confirmed the diagnosis of ectopic pancreas. There were no clinical signs of pancreatitis. No recurrence or metastasis was observed during a follow-up period of 3 years. English language medical literature was also searched in order to identify other case reports describing this rare condition and identified 17 papers describing 20 cases of anterior mediastinal ectopic pancreas, which were all confirmed at surgery. All clinical characteristics in these cases were reviewed.

\section{Introduction}

Heterotopia of pancreatic tissue is a developmental anomaly found in approximately $2 \%$ of all autopsies, but pancreatic tissue within the thorax and mediastinum is much less common (1). Because both the respiratory and digestive tracts are derived from primitive foregut, congenital cysts, whether bronchogenic, enteric, or duplication cysts, are considered to have a common enteric origin and can be regarded as malformations produced during differentiation and embryologic development of the primitive intestine. Enteric cysts in the thorax account for $20 \%$ of digestive tract duplications. Their structure consists of a smooth muscle layer and a gastrointestinal mucosal lining.
\end{abstract}

Correspondence to: Professor Gang Chen or Dr Jun Chen, Department of Lung Cancer Surgery, Tianjin Key Laboratory of Lung Cancer Metastasis and Tumor Microenvironment, Tianjin Lung Cancer Institute, Tianjin Medical University General Hospital, 154 Anshan Road, Heping, Tianjin 300052, P.R. China

E-mail: chengang450@163.com

E-mail: huntercj2004@yahoo.com

*Contributed equally

Key words: ectopic pancreas, anterior mediastinal mass, thoracoscopy
Only a few cases have been reported in the English language literature, all of them arising from the anterior mediastinum.

\section{Case presentation}

A 32-year-old woman was admitted for evaluation of an anterior mediastinal mass, which was incidentally identified on a chest X-ray. The mass was positioned above the aortic arch. Pre-contrast chest computed tomography (CT) showed a $3.6 \times 3.9 \mathrm{~cm}$ cystic-solid mass situated mainly on the left side of the anterior mediastinum. The wall of the cystic lesion showed moderate contrast enhancement, while the solid part of the lesion did not show marked enhancement (Fig. 1). Mindful that the patient was a young woman, we decided, after a full preoperative workup, to perform surgery via thoracoscopy and to excise the tumor. The tumor was completely resected via a right thoracoscopy so as to protect the superior vena cava and the left innominate vein. We found that the tumor was firmly adherent to the pericardium and the left pleura and was connected by a tenuous bridge of tissue to the thymus. Grossly, the mass measured $7 \times 4 \times 1.5 \mathrm{~cm}$ and was part solid and part cystic. Postoperative recovery was uneventful and the patient was discharged on postoperative day 7. After 3 years of follow-up, there was no evidence of recurrence (Fig. 1).

Histological examination of the mass showed that the cystic wall was composed of fibrous connective tissue lined with columnar epithelium, and immunohistochemical staining was positive for both CK19 and CK20. Pancreatic acini and islet cells were present, and immunohistochemical staining indicated positivity for alpha-ACT and islet cell insulin (Fig. 2). Therefore, the final pathology diagnosis was ectopic pancreas in the mediastinum with cystogenesis.

\section{Discussion}

Ectopic pancreas is the presence of pancreatic tissue outside of the normal pancreas that has no vascular or anatomical connections to the original organ but contains acinar cells and ducts and islets of Langerhans. Ectopic pancreas is usually found in the stomach, duodenum, jejunum, or ileum; it may also be found in the gallbladder, esophagus, common bile duct, spleen, and mesentery. However, ectopic pancreas in the mediastinum is a very rare. While the exact genesis of ectopic pancreas is not known, its position in the anterior mediastinum 
Table 1. Clinical features of mediastinal ectopic pancreas described in the literature.

\begin{tabular}{|c|c|c|c|c|c|c|c|c|}
\hline Year & Symptom & Sex & Age & $\begin{array}{c}\text { Tumor } \\
\text { size }(\mathrm{CM})\end{array}$ & $\begin{array}{l}\text { Gross } \\
\text { feature }\end{array}$ & Position & Incision & $\begin{array}{l}\text { Following-up } \\
\text { (M) }\end{array}$ \\
\hline 1957 (2) & Dyspnea & Female & 16 & 12 & Cystic & 1 & Median sternotomy & I \\
\hline 1977 (3) & No symptom & Female & 57 & $7 \times 6.5$ & Cystic & Left & Left thoracotomy & l \\
\hline $1996(4)$ & Heart murmur & Female & 16 & 12 & Cystic & l & Median sternotomy & / \\
\hline $2001(5)$ & Cough, chest pain & Female & 45 & $11 \times 8$ & Cystic & Left & Median sternotomy & 24 \\
\hline $2004(6)$ & Dyspnea & Male & 44 & $10 \times 8 \times 7.5$ & Cystic & Left & Median sternotomy & l \\
\hline $2005(7)$ & No symptom & Male & 39 & 10x8 & Cystic & Left & Median sternotomy & 96 \\
\hline $2006(8)$ & $\begin{array}{l}\text { Fever, neck swelling, } \\
\text { dyspnea }\end{array}$ & Male & 40 & $8 \times 6 \times 6$ & Cystic & Left & Median sternotomy & l \\
\hline 2007 (9) & Chest pain & Female & 17 & $12.5 \times 12.0 \times 4.5$ & Cystic & Right & Right thoracotomy & l \\
\hline 2007 (9) & $\begin{array}{l}\text { Chest pain, short of } \\
\text { breath }\end{array}$ & Female & 24 & $10 \times 8 \times 4$ & Cystic-solid & Right & Right thoracotomy & 1 \\
\hline $2009(10)$ & No symptom & Female & 32 & $16 \times 13 \times 8$ & Cystic-solid & Bilateral & Median sternotomy & 3 \\
\hline $2010(11)$ & $\begin{array}{l}\text { Chest pain, cough, } \\
\text { dyspnea }\end{array}$ & Male & 51 & $7.5 \times 7.0 \times 5.0$ & Cystic & Right & Median sternotomy & l \\
\hline $2010(11)$ & $\begin{array}{l}\text { Left shoulder pain, } \\
\text { dyspnea, hemoptysis }\end{array}$ & Male & 42 & l & Cystic-solid & Left & Left thoracotomy & 28 \\
\hline $2012(12)$ & Chest pain & Female & 66 & $\begin{array}{c}7.8 \times 4.6 \times 2.7 \\
\text { and } 10.8 \times 9.1 \times 3.7 \\
\text { (two pieces) }\end{array}$ & Cystic-solid & $\begin{array}{l}\text { No } \\
\text { mention }\end{array}$ & Median sternotomy & Death (15) \\
\hline $2012(13)$ & $\begin{array}{l}\text { Hemoptysis, } \\
\text { chest pain }\end{array}$ & Male & 32 & 1 & Cystic & Right & Median sternotomy & 24 \\
\hline $2012(14)$ & $\begin{array}{l}\text { Chest pain, mild } \\
\text { cough, blood-tinged } \\
\text { sputum }\end{array}$ & Female & 31 & $7 \times 3 \times 4$ & Cystic-solid & Left & Left thoracoscopy & l \\
\hline $2013(15)$ & Cervical mass & Female & 22 & $2.4 \times 3.8$ & Cystic & Cervical & Cervical approach & 48 \\
\hline $2014(16)$ & Dyspnea, stridor & Male & 18 & $16 \times 12 \times 9$ & Cystic & Left & Median sternotomy & l \\
\hline 2014 (17) & $\begin{array}{l}\text { Chest pain, cough, } \\
\text { fever }\end{array}$ & Male & 15 & $7 \times 4.5$ & Cystic-solid & Right & Median sternotomy & 96 \\
\hline 2014 (17) & $\begin{array}{l}\text { Throat discomfort, } \\
\text { neck swelling }\end{array}$ & Female & 16 & 6 & Cystic-solid & Median & Median sternotomy & 6 \\
\hline 2015 (18) & $\begin{array}{l}\text { Cough, chest pain, } \\
\text { shortness of breath }\end{array}$ & Male & 17 & $7.6 \times 7 \times 5.8$ & Solid & Left & Median sternotomy & l \\
\hline
\end{tabular}

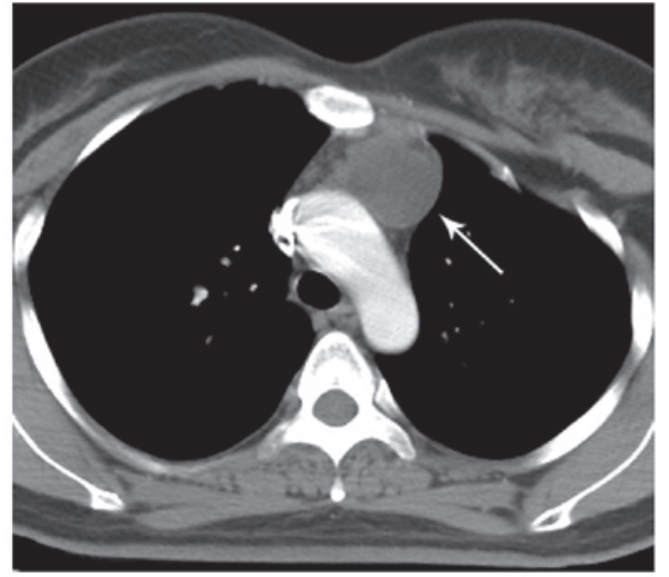

Figure 1. Chest CT. The preoperative scan shows a cystic-solid mass measuring $3.6 \times 3.9 \mathrm{~cm}$ and situated mainly on the left side of the anterior mediastinum; a follow-up scan at 3 years after surgery shows no tumor recurrence. CT, computed tomography. argues against a gastroenteric origin because lesions of gastroenteric origin normally occur in the posterior mediastinum.

We performed a PubMed search of the English language literature for papers relating to anterior mediastinal ectopic pancreas and found 17 such papers reporting a total of 20 cases (2-18), all of which were confirmed at surgery (Table I). Most of these reports were from Asian countries, with others from Europe and North America. Women slightly outnumbered men, and the average age was 32 years. The common presenting symptoms were chest pain, dyspnea, and cough. Other symptoms were neck swelling, heart murmur, and hemoptysis. There were very few patients who were entirely asymptomatic. The nature of the presenting symptoms was closely correlated with the size and location of the tumor, and the largest reported tumor diameter was $16 \mathrm{~cm}(10,16)$. In most of the cases, the chest CT showed a cystic or cystic-solid mass, with only one pure solid mass reported (18). There was often moderate enhancement of the cyst wall on the post-contrast 


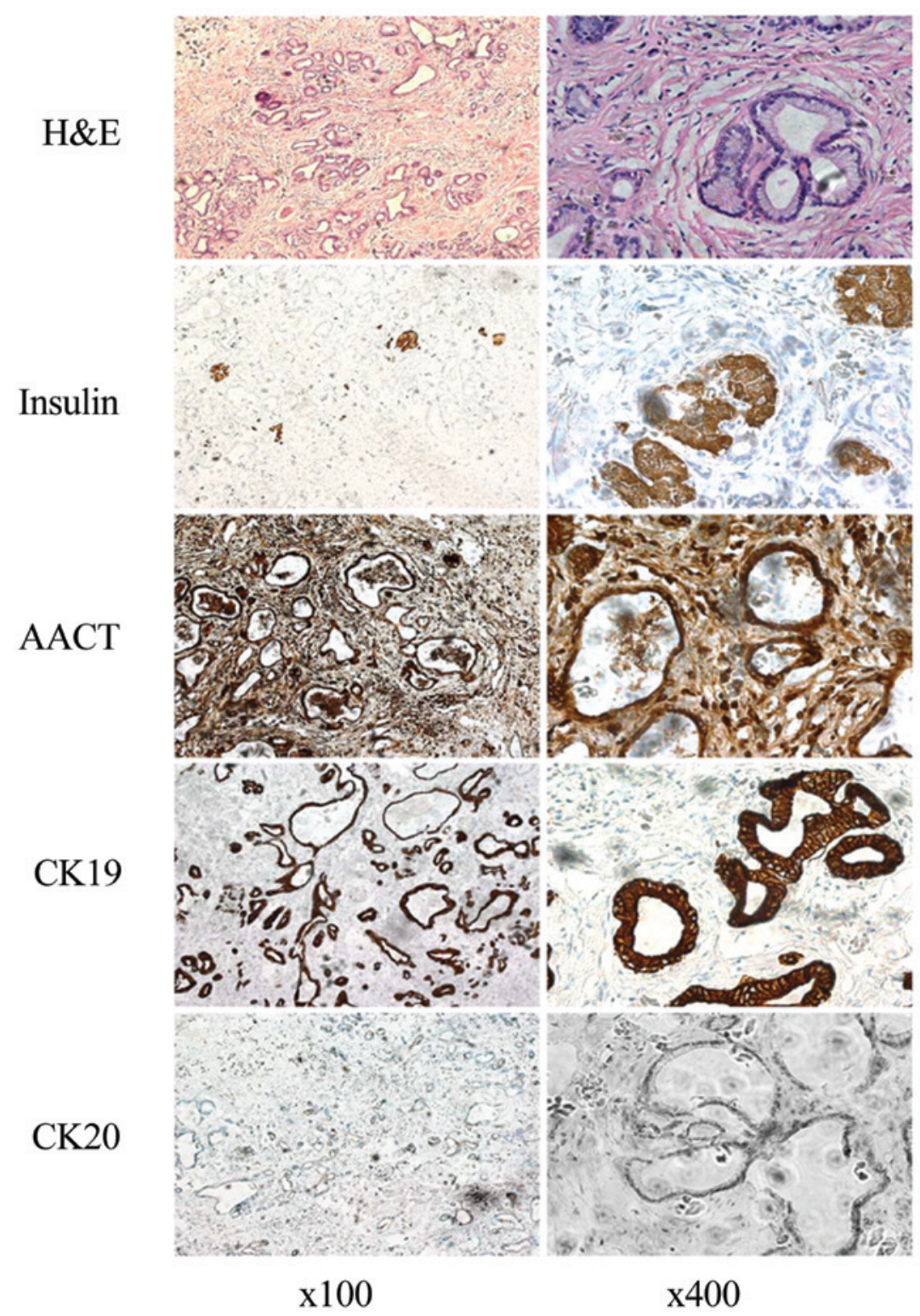

Figure 2. Hematoxylin/eosin staining and immunohistochemistry. Microscopy shows a normal acinar structure in the solid portion of the mass and pancreatic acini and islet cells in the wall of the cystic portion. Immunostaining is positive for islet cell insulin and cystic alpha-ACT, CK19, and CK20.

$\mathrm{CT}$, and some cases showed enhancement of the solid part of the lesion. Arriving at a precise diagnosis preoperatively was difficult, and provisional diagnoses included thymoma, lymphoma, mediastinal thyroid, and abscess, depending on the CT appearance (19). Although several of these patients underwent preoperative biopsy, almost all of the cases were definitively diagnosed only after complete surgical resection, which is feasible without a definitive diagnosis when the mass is considered resectable (20).

Anterior mediastinal ectopic pancreas is most often benign, and surgery is curative in most cases. However, there is a report of an aggressive adenocarcinoma arising from ectopic pancreas in the anterior mediastinum, which metastasized to the anterior sternum 6 months after resection of the primary tumor (12). The disease progressed rapidly, and the patient died within 15 months after the initial presentation, despite tumor debulking and postoperative adjuvant treatment. Because of the risk of malignant transformation of ectopic pancreas in the anterior mediastinum, surgical treatment should be planned without delay, and awareness of the possibility of the rare occurrence of adenocarcinoma arising from ectopic pancreas in the anterior mediastinum can help prevent misdiagnosis.

The majority of patients with ectopic pancreas in the anterior mediastinum have had curative resection by median sternotomy, or by thoracotomy where the main tumor has penetrated into one side of the chest. Besides our patient, thoracoscopy has been used for complete resection in one other case, in South Korea (14). The surgical approach to resection of anterior mediastinal masses has traditionally been based on studies of thymectomy, and advances in minimally invasive surgery have challenged the dictum of median sternotomy as the approach of choice. When compared with sternotomy, both video-assisted thoracoscopic surgery (VATS) and robot-assisted thoracoscopic surgery (RATS) have been associated with better estimation of the relationship of the tumor with adjacent structures, decreased intraoperative blood loss, decreased length of hospital stay, and reduced postoperative pain (21). The present study selected chose thoracoscopy in 
our case after careful consideration of the patient's age and the size and location of the tumor.

In summary, the possibility of ectopic pancreas should be considered when a patient presents with a cystic or cystic-solid mass in the anterior mediastinum. Ectopic pancreas in the anterior mediastinum is rare and infrequently reported, and it is difficult to diagnose without biopsy. Our experience confirms that prompt surgical resection is beneficial for affected patients. As medical technology progresses, new surgical techniques may bring further advances, and this too should be fully considered.

\section{Acknowledgements}

Not applicable.

\section{Funding}

The study was partially supported by grants from the National Natural Science Foundation of China (grant nos. 81773207 and 61573251) and the Tianjin Natural Science Foundation (grant nos. 16PTSYJC00160 and 16JCZDJC34200). These bodies had no role in the study design, data collection and analysis, decision to publish, or in the preparation of the manuscript.

\section{Availability of data and materials}

The datasets used and/or analyzed during the present study are available from the corresponding author on reasonable request.

\section{Authors' contributions}

HZhao and JC wrote this manuscript and analyzed all of the data. XL, ZZ, JL and HZhang provided medical care for the patients and collected the data. GC performed the operation. GC and JC revised the article. All authors read and approved the final manuscript.

\section{Ethics approval and consent to participate}

The present study was approved by the Ethical Review Committee of Tianjin Medical University General Hospital. Written informed consent was obtained from the patient for the publication of this case report and the accompanying images. A copy of the consent form is available for review by the Editor-in-Chief of this journal.

\section{Patient consent for publication}

Written informed consent was obtained from the patient for the publication of this case report and the accompanying images.

\section{Competing interests}

The authors declare that they have no competing interests.

\section{References}

1. Lai EC and Tompkins RK: Heterotopic pancreas: Review of a 26 year experience. Am J Surg 151: 697-700, 1986.

2. Shillitoe AJ and Wilson JE: Enterogenous cyst of thorax with pancreatic tissue as a constituent. J Thorac Surg 34: 810-814, 1957.

3. Carr MJT, Deiraniya AK and Judd PA: Mediastinal cyst containing mural pancreatic tissue. Thorax 32: 512-516, 1977.

4. Perez-Ordonez B, Wesson DE, Smith CR and Asa SL: A pancreatic cyst of the anterior mediastinum. Mod Pathol 9: 210-214, 1996.

5. Cagirici U, Ozbaran M, Veral A and Posacioglu H: Ectopic mediastinal pancreas. Eur J Cardiothorac Surg 19: 514-515, 2001.

6. Iglesias Sentís M, Belda Sanchís J, Gimferrer Garolera JM, Catalán Biela M, Rubio Garay M and Ramírez Ruz J: Mediastinal enteric cyst: Unusual clinical presentation and histopathology. Arch Bronconeumol 40: 185-187, 2004 (In Spanish).

7. Tamura Y, Takahama M, Kushibe K and Taniguchi S: Ectopic pancreas in the anterior mediastinum. Jpn J Thorac Cardiovasc Surg 53: 498-501, 2005.

8. Al-Salam S and Al Ashari M: Ectopic pancreatic tissue in the anterior mediastinum. Virchows Arch 448: 661-663, 2006.

9. Wang W, Li K, Qin W, Sun H and Zhao C: Ectopic pancreas in mediastinum: Report of 2 cases and review of the literature. J Thorac Imaging 22: 256-258, 2007.

10. Chen ZH, Yu RS, Dong F and Wang XJ: CT findings of an ectopic pancreas in the anterior mediastinum. Korean J Radiol 10: 527-530, 2009.

11. Fayoumi S, Al-Husseini L, Jalil R and Abbasi S: Ectopic pancreatic tissue in the thoracic cavity: Report of two cases. Ann Thorac Surg 90: e25-e27, 2010.

12. St Romain P, Muehlebach G, Damjanov I and Fan F: Adenocarcinoma arising in an ectopic mediastinal pancreas. Ann Diagn Pathol 16: 494-497, 2012.

13. Szabados S, Lénárd L, Tornóczky T, Várady E and Verzár Z: Ectopic pancreas tissue appearing in mediastinal cyst. J Cardiothorac Surg 7: 22, 2012.

14. Byun CS, Park IK, Kim H and Yu W: Ectopic pancreas with hemorrhagic cystic change in the anterior mediastinum. Korean J Thorac Cardiovasc Surg 45: 131-133, 2012.

15. Rokach A, Izbicki G, Deeb M, Bogot N, Arish N,Hadas-Halperen I, Azulai H, Bohadana A and Golomb E: Ectopic pancreatic pseudocyst and cyst presenting as a cervical and mediastinal mass: Case report and review of the literature. Diagn Pathol 8: 176, 2013.

16. Li WW, van Boven WJ, Jurhill RR, Bonta PI, Annema JT and de Mol BA: Ectopic pancreas in a giant mediastinal cyst. Clin Respir J 10: 125-128, 2016.

17. Zhang L, Peng LQ, Yu JQ, Yuan HM, Chu ZG, Zeng HJ and Wei B: Ectopic pancreas in the anterior mediastinum: A report of two cases and review of the literature. Oncol Lett 7: 1053-1056, 2014.

18. Koh HM, Chang JW, Jeong SY, Hyun CL, Kim YS, Jang BG and Maeng YH: Ectopic pancreas presenting as a solid mediastinal mass. Int J Surg Pathol 23: 585-588, 2015.

19. Carter BW, Marom EM and Detterbeck FC: Approaching the patient with an anterior mediastinal mass: A guide for clinicians. J Thorac Oncol 9 (9 Suppl 2): S102-S109, 2014.

20. Hakiri S, Kawaguchi K, Fukui T, Nakamura S, Ozeki N, Mori S, Goto M, Hashimoto K, Ito T and Yokoi K: Verification of the diagnostic strategy for anterior mediastinal tumors. Int J Clin Oncol 24: 385-393, 2019.

21. Mortman KD and Chaffee SB: Robotic-assisted thoracoscopic resection of a benign anterior mediastinal teratoma. J Robot Surg 7: 401-403, 2013. 